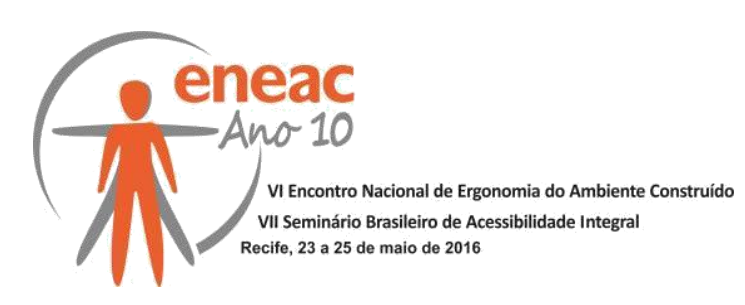

\title{
ACESSIBILIDADE INCLUSIVA NO PARQUE INFANTIL ARRUDA CÂMARA
}

\author{
(1) MEDEIROS, Adriana Araujo; \\ (2) Albuquerque, Cláudia Galdino Macêdo; \\ (3) JÚNIOR, Aarão Pereira Araujo; \\ (4) MAIOR, Mônica Maria Souto \\ (1) IFPB, Graduada em Tecnologia Design de Interiores \\ e-mail: aamedeiros@live.com \\ (2) IFPB, Graduada em Tecnologia Design de Interiores \\ e-mail: klaudiagaldino@yahoo.com.br
}

\author{
(3) IFPB, Doutor \\ e-mail: aaraoaraujo@yahoo.com.br \\ (4) IFPB, Doutora \\ e-mail: mmsmaior@hotmail.com
}

\begin{abstract}
RESUMO
O indivíduo sem qualquer deficiência esteja em um ambiente hostil e inacessível, pode ser considerado deficiente para esse espaço. Portanto, quando a pessoa com deficiência está em um ambiente acessível, suas atividades são preservadas, e sua deficiência não afeta suas funções. Desta maneira, a acessibilidade pode ser entendida também como: possibilidade de acesso, da aproximação, da utilização e do manuseio de qualquer ambiente, onde a localização do parquinho infantil do Parque Zoobotânico Arruda Câmara, tendo como objetivo indicar elementos já existentes, que promova, a segurança, a autonomia, o desenvolvimento cognitivo-sensorial, a integração das crianças utilizando os princípios do Design Universal.
\end{abstract}

Palavras chave: Parques públicos; Acessibilidade; Crianças.

\begin{abstract}
The individual without any disability is in a hostile and inaccessible environment can be considered disabled for that space. Therefore, when the disabled person is in an accessible environment, their activities are preserved, and their disability does not affect their function.

In this way, accessibility can also be understood as access on the approach, the use and any environment handling, where the location of the playground of the Zoo and Botanical Park Arruda Camara, aiming to indicate existing elements to promote, security, autonomy, cognitive - sensory development, the integration of children using the principles of universal design .
\end{abstract}

Keywords: Public park; Accessibility; Children.

\section{INTRODUÇÃO}




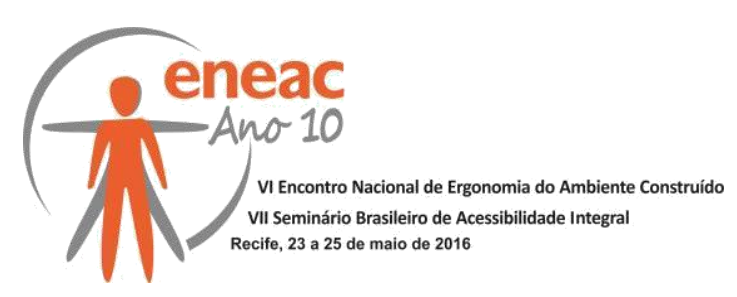

A acessibilidade é o principal meio para a inclusão social, porque permite a todos com deficiências físicas, metais, o acesso e a liberdade de utilização dos espaços, além de incluir livremente todos a várias atividades como educação, lazer e cultura.

E percebe-se também que a acessibilidade não visa apenas que pessoas com suas mobilidades reduzidas interajam em qualquer atividade com segurança e autonomia, mas que haja inclusão e extensão a toda a população de qualquer faixa etária, visando sua locomoção e adaptação, eliminando barreiras.

No Brasil, o Censo do IBGE de 2000 mostra que cerca de 24,5 milhões de pessoas $(14,5 \%$ da população total) apresentam algum tipo de incapacidade ou deficiência. São as pessoas com ao menos alguma dificuldade de enxergar, de ouvir, locomover-se ou com alguma deficiência física ou mental. Dentre os diversos níveis de incidência das deficiências podemse destacar: a deficiência visual - não necessariamente cegueira total - é o mais presente nos brasileiros, representando quase a metade $(48,1 \%)$ da população com deficiência. Logo em seguida vêm as deficiências motoras e físicas que, em conjunto, somam $27,1 \%$. A terceira maior incidência é a deficiência auditiva (16,6\%) considerada os diferentes graus de perda auditiva, desde a surdez leve até anacusia - e por último, aparece a deficiência mental, que atinge $8,2 \%$ do total de indivíduos com deficiência.

Diante deste quadro quantitativo, surgem medidas que possam permitir a inclusão deste público a equipamentos de lazer, possibilitando-os autonomia e igualdade de direitos a diversão. Diante desta assertiva, busca-se com este projeto, do parque de diversão acessível, possibilitar as crianças e adolescentes o acesso a equipamentos que gerem a diversão, mas que também sirvam como meio de educação e atividade físico-motora. Essa medida se justifica pela obrigatoriedade gerada pela Lei oㅜ 10.098 de 19 de Dezembro de 2000, que estabelece que os parques de diversões, públicos e privados, devem adaptar, no mínimo, 5\% (cinco por cento) de cada brinquedo e equipamento e identificá-lo, para possibilitar sua utilização por pessoas com deficiência ou com mobilidade reduzida, tanto quanto tecnicamente possível. (Incluído pela Lei no 11.982, de 2009).

Para que seja desenvolvida uma obra completamente acessível, que contemple a todos os portadores de deficiência e todas as pessoas com mobilidade reduzida, um trajeto livre e seguro, é importante se criar projetos com estudos de caso, avaliações, pesquisas e análises críticas a respeito de cada espaço a ser trabalhado. Não é uma visão restrita e sim uma interdisciplinaridade, ou seja, com conjunto de profissionais de várias áreas trabalhando juntos para garantir o melhor conceito e projeto possível.

\section{LAZER E QUALIDADE DE VIDA}

Acessibilidade é fruto da busca constante pela inclusão, ou seja, é um processo, pelo acesso universal a ambientes, e a aplicação da acessibilidade resulta em ambientes universais, concebidos para atender a todas as pessoas, trazendo benefícios para toda a sociedade independente também de sua faixa etária. $E$ a acessibilidade é um resultado da prática do design inclusivo e o desenho universal representando o seu nível mais amplo. Esta, não pode ser pensada como uma solução específica para atender pessoas com deficiência ou com mobilidade reduzida e sim com parâmetros complexos de bem estar e qualidade de vida a todos.

Há cerca de trinta anos houve um aumento considerável, de forma mundial, nas adaptações para pessoas com deficiência. E o Brasil evoluiu com esta tendência de inclusão (PRADO, LOPES, ORNSTEIN, 2010). Mas segundo Stainback, 1999, a concepção da inclusão 


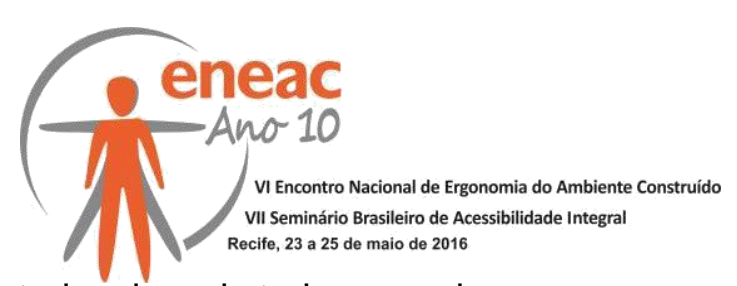

abrange a união de um todo, de unir todas as crianças e presenciar a aprendizagem de todas juntas.

E o lazer é um componente importantíssimo na qualidade de vida de pessoas com necessidades especiais, possibilitando assim a integração comunitária, o aumento da autoestima, como a possibilidade também de novas potencialidades através de autonomia e segurança. Muitos para olímpicos descobriram suas habilidades atléticas através de atividades de lazer.

Associar acessibilidade com 0 ato de brincar permite a criança portadora de limitação o direito de usufruir de espaços lúdicos que são muito importantes para o processo de construção e desenvolvimento de habilidades, capacidades e potencialidades, além de contribuir para a aquisição da cultura e promover a integração entre os seus aspectos físicos, emocionais, afetivos, cognitivos e sociais (BRASIL, 1998b; CRUZ; PFEIFER, 2006; DISCHINGER et al., 2008).

Os parques infantis são constituídos por brinquedos que devem dar suporte ao brincar, preencher e satisfazer as necessidades de cada criança (VIGOTSKI, 1998; BRASIL, 1998b). Tais brinquedos são considerados elementos destinados a criar oportunidades específicas para os alunos brincarem, se socializarem e aprenderem (UNITED STATES ACCESS BOARD, 2005).

Os brinquedos podem ser de diferentes origens, formas, texturas, tamanhos, cores, assim como também podem ser únicos ou compor uma parte da estrutura de um parque (BRASIL, 1998b; UNITED STATES ACCESS BOARD, 2005).

No Brasil o primeiro parque infantil acessível foi inaugurado em 25 de janeiro deste ano, na cidade de São Paulo, numa unidade da AACD (Associação de assistência à criança com deficiência), no Parque a Mooca. E foi criado com recursos próprios, pelo Senhor Rudi Fisher. O mesmo decidiu criar este parque infantil após a perda trágica de sua filha Anna Laura, em um acidente de carro. Após o ocorrido Fisher se aprofundou no judaísmo e sentiu a necessidade de fazer algo positivo para crianças que necessitassem. $E$ foi em Jerusalém, que o mesmo conheceu um escorregador adaptado para crianças portadoras de necessidades físicas.

Então Fisher decidiu criar o primeiro parque infantil acessível da cidade de São Paulo, e contou com ajuda para elaboração dos brinquedos de fisioterapeutas, engenheiros e arquitetos (todos de forma voluntária). E batizou o parque de Anna Laura Parque para Todos. No parque há quinze brinquedos que contemplam crianças com dificuldades motoras e cadeirantes. Fisher gastou no primeiro parque o valor de cento e vinte mil e pretende abrir outros parques em Santo Amaro, Recife e Porto Alegre.

Segundo os documentos que apresentam recomendações para a construção de Parques Infantis adaptados (WERNER, 1994; PORTUGAL, 1997; BRASIL, 1998b; LAUFER, 2001; UNITED STATES ACCESS BOARD, 2005; DAHROUJ, 2006; BRENDLER; BRONDANI; SENA; 2007), os parques infantis devem contemplar os seguintes aspectos:

- Apresentar elementos recreativos para diferentes faixas etárias, e que abarque diferentes limitações físicas e sensoriais, com diversos tipos de brinquedos, que estimulem diferentes usos e atividades;

- A rota dos equipamentos do parque infantil que estão no mesmo nível do chão deve estar conectada tanto aos equipamentos desse nível quanto ao sistema de transferência dos equipamentos com elevação. Essa rota não deve possuir objetos que dificultam ou impedem a locomoção das crianças; 


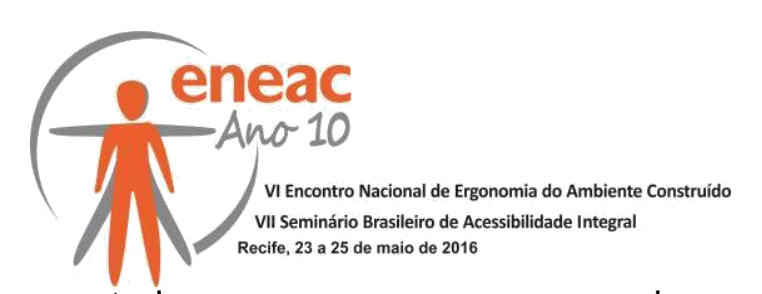

- Os desníveis apresentados como as rampas, escadas ou outros equipamentos, devem ser formados por guias e corrimãos. Caso o corrimão se torne um risco, recomenda-se a sua retirada;

- Os equipamentos com elevação devem possuir pelo menos $50 \%$ das suas entradas e saídas acessíveis à rota que os compõe;

- Em cada nível do equipamento do parque infantil, deve ser fornecido pelo menos um espaço para manobra de 180ㅜ

Dentre os vários parâmetros apresentados e recomendados para parques infantis nestas literaturas, observa-se que existem ainda alguns parâmetros que devem ser considerados que incluam crianças com deficiência visual, auditiva e sensorial, as quais são esquecidas na maioria dos estudos e pesquisas que envolvem a acessibilidade.

Deve-se levar em consideração o desuso da Tecnologia Assistiva, que por muitas vezes projeta-se equipamentos para uso permanente, mas sem um longo e cauteloso estudo o mesmo fica sem atender as necessidades propostas e tornam-se sem uso. Segundo( Phillips e Zhao, 1993, Scherer, 2002, Craddock, 2002, Hocking, 1999, Maia, Niemeyer e Freitas, 20), para se projetar um maquinário necessita-se de envolvimento do usuário, para que o mesmo possa mostrar as reais necessidades e assim fazer com que os projetistas possam atender suas expectativas.

A participação de terapeutas ocupacionais e de fisioterapeutas são importantíssimos neste processo, pois os mesmos ouvem os anseios das pessoas com deficiências, e ajudam através desses relatos, criar equipamentos que cheguem o mais perto possível do almejado pelos usuários. E segundo (Marllin, 2004), é essencial a presença de designers, pois os projetos sem esses profissionais são poucos humanizados, sem ergonomia, sem uma estética que chame a atenção das crianças e muitas vezes sem tecnologia.

O fator mais importante é propiciar a integração e inclusão da criança com deficiência com as que não têm deficiência dentro de um universo mais propicio para o seu desenvolvimento que são os parques infantis, mesmo sendo eles dentro das escolas ou em ambientes públicos.

\section{DESIGN UNIVERSAL}

Mesmo que um indivíduo sem qualquer deficiência esteja em um ambiente hostil e inacessível, este pode ser considerado deficiente para esse espaço. Portanto, quando a pessoa com deficiência está em um ambiente acessível, suas atividades são preservadas, e sua deficiência não afeta suas funções. Mas os produtos e ambientes feitos com desenho inclusivo ou acessível, não precisam ser unicamente destinados a pessoas com deficiência e sim a todos que façam parte do recinto (SASSAKI, 1999).

Há alguns anos, notou-se que algumas pessoas, mesmo sem deficiência física, enfrentavam dificuldades com o ambiente. Então se criou a expressão: pessoas com mobilidade reduzida, para definir o grupo social com problemas de acesso e utilização dos ambientes construídos. Segundo (Cambiaghi, 2007), essa denominação inclui pessoas com deficiência, crianças, idosos, pessoas carregando pacotes, empurrando carrinho de bebês, carrinhos de compras e aquelas que estão com alguma lesão temporária, ou fases passageiras como a gestação.

São de total relevância a independência, autonomia e dignidade do cidadão no ambiente em que o mesmo vive, como sociedade e como indivíduo. Mas infelizmente a realidade dos 


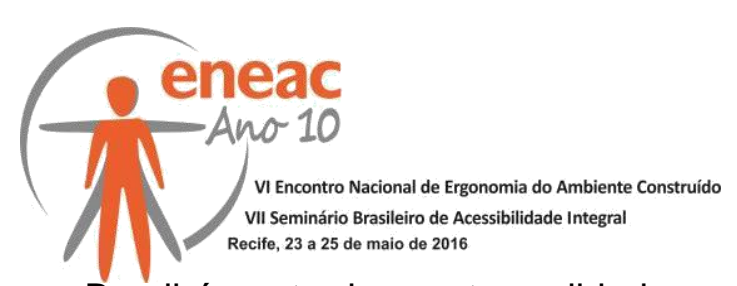

portadores de deficiência no Brasil é contraria a esta realidade, pois até o direito de ir e vir nas calçadas não é uma atividade simples, sofrendo desta maneira uma exclusão social.

Desta maneira, a acessibilidade pode ser entendida também como: possibilidade de acesso, da aproximação, da utilização e do manuseio de qualquer ambiente ou objeto. Levando em consideração a forma de deslocamento para se chegar a um ambiente desejado. Segundo a NBR 9050 (2004), a acessibilidade é a possibilidade e a condição de alcance, percepção e entendimento para utilização com segurança e autonomia de edificações, espaços, mobiliário, equipamento urbano e elementos.

As pessoas que por algum motivo estejam limitadas, temporariamente ou definitivamente de executar seus movimentos, devem ter o direito à liberdade e autonomia em qualquer ambiente, mesmo que seja utilizando maquinários específicos para isso, como cadeira de rodas ou muletas ou até mesmo bengalas. Mas o direito ao deslocamento deve ser priorizado não deixando as mesmas impedidas nem limitadas. Portanto, observando esta necessidade, na realização de um projeto em Desenho Universal deve-se obedecer aos 7 princípios básicos, que são (CAMBIAGHI,2007)

1. Utilização equitativa: pode ser utilizado por qualquer grupo de utilizadores;

2. Flexibilidade de utilização: Engloba uma gama extensa de preferências e capacidades individuais;

3. Utilização simples e intuitiva: fácil de compreender, independentemente da experiência do utilizador, dos seus conhecimentos, aptidões linguísticas ou nível de concentração;

4. Informação perceptível: Fornece eficazmente ao utilizador a informação necessária, qualquer que sejam as condições ambientais/físicas existentes ou as capacidades sensoriais do utilizador;

5. Tolerância ao erro: minimiza riscos e consequências negativas decorrentes de ações acidentais ou involuntárias;

6. Esforço físico mínimo: pode ser utilizado de forma eficaz e confortável com um mínimo de fadiga;

7. Dimensão e espaço de abordagem e de utilização: Espaço e dimensão adequada para a abordagem, manuseamento e utilização, independentemente da estatura, mobilidade ou postura do utilizador.

Segundo o Ministério Nacional para Reabilitação, foi observado que em algum momento da vida o indivíduo ficará, temporário ou definitivamente, com alguma limitação física, portanto o que se deseja, é a conscientização da sociedade para um país mais igualitário do ponto de vista de acesso para todos. No Brasil, infelizmente não existe um estudo aprofundado de quantos indivíduos tem sua mobilidade reduzida, mas segundo a OMS, em países desenvolvidos, $10 \%$ da população têm algum tipo de deficiência e segundo o censo norteamericano, 20\% da população apresentam algum tipo de deficiência.

Atualmente, há muitas discussões sobre a inclusão social e a necessidade de uma arquitetura e de um design inclusivo, porque a exclusão no nosso país a épocas atrás teve um peso muito considerável. Esta exclusão era vista nos próprios ambientes da educação, na saúde, no trabalho, no transporte tanto privado quanto público, na cultura e no lazer.

Então surge a importância do desenho universal, mas o seu conceito vem sendo utilizado de forma inadequada, pois o mesmo, mostra apenas como aplicação de normas técnicas, para tornar objetos acessíveis. E isto torna as criações, em objetos pobres e com problemas de acessibilidade. O desenho universal é responsável pela criação de ambientes ou produtos 


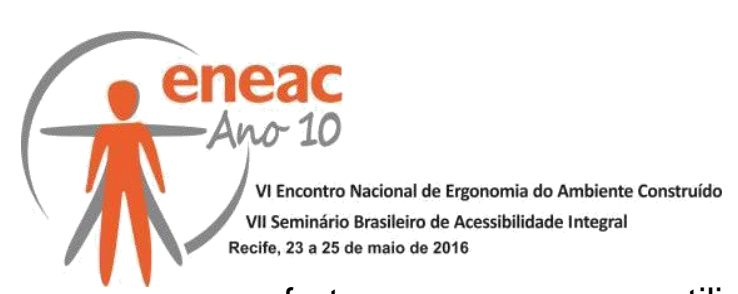

de excelente qualidade, segurança e conforto, que possam ser utilizados pelo maior número de pessoas.

O desenho universal emergiu como consequência das reinvindicações de dois segmentos sociais diversos: dos movimentos de pessoas com deficiência, que sentiam suas necessidades colocadas à margem por profissionais das áreas de construção e arquitetura, e da iniciativa de alguns arquitetos, urbanistas e designers, que pretendiam uma maior democratização dos valores e uma visão mais ampla na concepção.

Para elaboração de projeto devem ser obedecidos os sete princípios e suas diretrizes do desenho industrial que são: Equiparação nas possibilidades de uso, Flexibilidade no uso, Uso simples e intuitivo, Informação perceptível, Tolerância ao erro, Mínimo esforço físico e dimensionamento de espaços para uso de todos os usuários. Isso para atingir o objetivo de promover a qualidade de vida.

Os profissionais de arquitetura e design estão diretamente ligados à criação de ambientes e produtos, e estes devem estar sempre atualizados as novas tecnologias e materiais, reduzir o tempo de elaboração do programa de necessidades dos produtos ou serviços, maximizar as possiblidades de êxito do produto, na medida em que este estar em situação de vantagem perante outros profissionais por seus conceitos satisfazerem a uma porcentagem maior de usuários e isso para mostrar os melhores resultados aos seus clientes.

\section{CARACTERIZAÇÃO DO OBJETO DE ESTUDO}

É um jardim zoobotânico localizado em João Pessoa, Paraíba. Com uma área de aproximadamente 26,8 hectares. O parque é popularmente chamado Bica, em virtude de uma fonte natural de água potável em seu centro. Nele, estão localizadas partes remanescentes da Mata Atlântica. Dentro do parque funciona a Escola do Meio Ambiente "Walfredo Guedes Pereira" que é ligada a Secretaria da Educação e Cultura do Município (Rodriguez, 1992). O parque é tombado pelo IPHAEP (Instituto do Patrimônio Histórico e Artístico do Estado da Paraíba) desde 26 de agosto de 1980.

O parque apresenta um orquidário, um museu e dois miniparques de diversões para as crianças, (um na parte central do parque, próximo ao habitat dos jacarés e outro na parte final do parque, próximo a lagoa) onde os mesmos são os objetos deste estudo. E também, para as crianças, apresenta charretes puxadas por pôneis e uma espécie de ônibus trenzinho guiado por um trator e um pedalinho que atravessa uma lagoa dentro do parque. Além desses atrativos este parque possui estacionamento próprio, lanchonetes, banheiros e toda a estrutura de apoio, como telefones e guias. Seu horário de funcionamento é das 8 às 17 horas, todos os dias, exceto na segunda-feira.

\section{Levantamento e coleta de dados}

Os dados foram levantados de forma secundária para conhecimento e identificação do real funcionamento de um parque infantil acessível identificar o melhor local de implantação; e primária para detectar as reais necessidades dos usuários do parque infantil acessível; desta forma podemos descrevê-los, da seguinte forma:

a) Levantamento secundário de dados - inicialmente foi feito um levantamento bibliográfico sobre o Parque Arruda Câmara, design universal e acessibilidade para uma melhor caracterização do estudo, bem como, para desenvolvimento do corpo teórico da pesquisa. Em seguida, buscamos nos órgãos competentes as plantas baixas e topográfica 


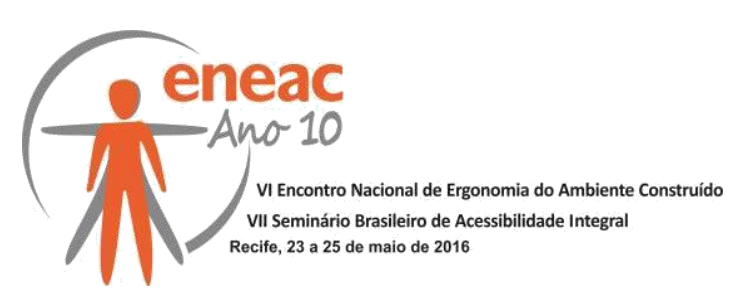

do Parque Arruda Câmara (BICA), para reconhecimento dos desníveis existentes, para possibilitar uma melhor escolha do local de implantação do parque acessível infantil.

b) Levantamento primário - Foram feitas visitas exploratórias para reconhecimento do local e observação dos aspectos relevantes para acessibilidade espacial e visualização da rotina de uso e as principais necessidades das crianças usuárias. E por fim aplicação de entrevistas com usuários, utilizando como amostra país das crianças e funcionários, visando o conhecimento das necessidades cognitivas e físicas dos pequenos portadores de limitações e aspirações dos pais e funcionários em relação a um parque de lazer acessível.

c) Como critérios de inclusão dos entrevistados foram escolhidos os pais de crianças, sendo os mesmos maiores de idade e alfabetizados; e os funcionários, maiores de idade, alfabetizados, contratados ou estagiários do Parque Arruda Câmara.

\section{ANALISES E DISCURSOES}

\subsection{Entrevistas direcionada aos pais de crianças deficientes}

Segundo o questionário aplicado aos pais, a faixa etária da maioria das crianças deficientes que brincam no Parque Infantil do Parque Arruda Câmara varia entre cinco a dez anos. E a deficiência mais presente neste grupo entrevistado foi a Deficiência Mental e a Física, chegando a um percentual de $70 \%$. A maioria das crianças apresentou a deficiência desde 0 nascimento.

Foi verificada pouca frequência de crianças no Parque infantil da Bica. Porém a maioria das mães relataram que as crianças gostam de brincar no parquinho, e este dado foi observado em um percentual de $90 \%$ das entrevistas. E o brinquedo já existente no parquinho que as crianças mais gostam de brincar são o escorrego e o balanço.

Para maior aprofundamento de questões sobre autonomia, foi perguntado aos pais se os seus filhos conseguem brincar nos aparelhos com autonomia e a maioria dos pais responderam que sim. Porém houve uma contradição em relação à segunda resposta que os mesmos afirmam não conseguir colocar dois ou mais filhos deficientes para brincar no parquinho ao mesmo tempo, mostrando com isso que as crianças não conseguem brincar nos aparelhos com autonomia.

Uns percentuais de $75 \%$ dos pais relataram que a maior dificuldade que os mesmos e seus filhos encontraram em relação ao parquinho é fazer o percurso até o mesmo e a segunda maior dificuldade é se manter nos brinquedos com segurança. E 100\% dos pais relataram que seus filhos não têm força suficiente para impulsionar os brinquedos sozinhos. $E$ um percentual de $65 \%$ dos pais relataram que os brinquedos não têm altura adequada para faixa de altura dos seus filhos.

Para maior aprofundamento sobre a segurança foi perguntado aos pais se eles consideram os brinquedos seguros, e um percentual de $85 \%$ respondeu que não, e justificaram que os brinquedos são desconfortáveis.

Uns percentuais de $95 \%$ dos pais responderam que nunca viu uma criança deficiente sendo vítima de algum acidente quando estavam brincando no parquinho da Bica. E $90 \%$, respondeu que há uma má conservação dos brinquedos. E 100\% respondeu que acha o trajeto dentro do parquinho inseguro. Sendo que ,90\% responderam que não acham seguro brincar no parquinho, tanto nos brinquedos quanto ao redor dos equipamentos. A maioria 


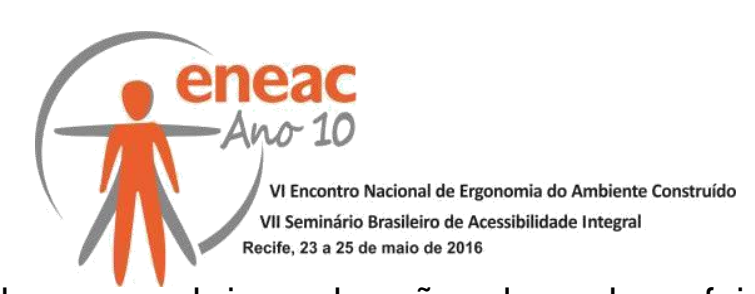

dos pais (70\%) respondeu que os brinquedos são adequados a faixa etária dos seus filhos, porem o tamanho dos brinquedos são inadequados.

A maioria dos pais (60\%) acham que as cores dos brinquedos estimulam e atraem a atenção dos seus filhos porem estão precisando de uma nova pintura. $E$ todos os pais relataram que o brinquedo que sugerem para promover o desenvolvimento dos seus filhos seja o balanço.

\subsection{ENTREVISTA DIRECINADA AOS FUNCIONÁRIOS DO PARQUE ARRUDA CAMARA}

Foi perguntado com que frequência os funcionários veem crianças com deficiência brincando no parquinho da Bica, e $90 \%$ responderam que menos de uma vez por mês. $\mathrm{E}$ a maioria $(90 \%)$ dos funcionários relataram que observam dificuldades das crianças brincarem nos brinquedos porque os mesmos são altos e o piso é de areia fofa dificultando a locomoção de cadeirantes. A maioria dos funcionários (90\%) relatam que o local onde 0 parquinho se localiza é adequado, porem $80 \%$ observam dificuldades no trajeto para chegar ao parquinho e percorrer algum trajeto dentro dele.

Todos os funcionários não escutaram nenhum relato dos pais, sobre a melhoria dos equipamentos do parquinho, para que pudesse ter uma otimização no desenvolvimento das crianças, e nunca presenciaram nenhum acidente de criança deficiente no parquinho. Relataram que a maioria das crianças deficientes que frequentam o parquinho apresentam deficiência visual.

E o brinquedo preferido das crianças deficientes são o escorrego e o balanço. E a sugestão que os funcionários relatam para melhoria do parquinho é melhoria do escorrego, pois o mesmo é muito alto e sem conforto ou segurança.

Para uma melhor compreensão de como seria o trajeto de uma criança deficiente da entrada do Parque Arruda Câmara até o primeiro Parque Infantil, que se localiza ao lado do recinto dos repteis, necessitou-se de um deficiente físico, que de forma voluntaria, percorreu todo o trajeto, da entrada até o parquinho e dentro do parquinho, analisando cada brinquedo e sugerindo equipamento que estariam acessíveis.

Segundo o relato do cadeirante, a ladeira de entrada é muito inclinada, o que impossibilita o trajeto de um cadeirante. Após o final da ladeira o trajeto até o parquinho aconteceria de autônoma se o piso continuasse asfaltado, porém como o piso não é liso, neste trajeto, há possibilidades de um cadeirante vir a sofrer um tombo (Foto 01).

Figura 01: Entrada do Parque Zoobotânico Arruda Câmara.

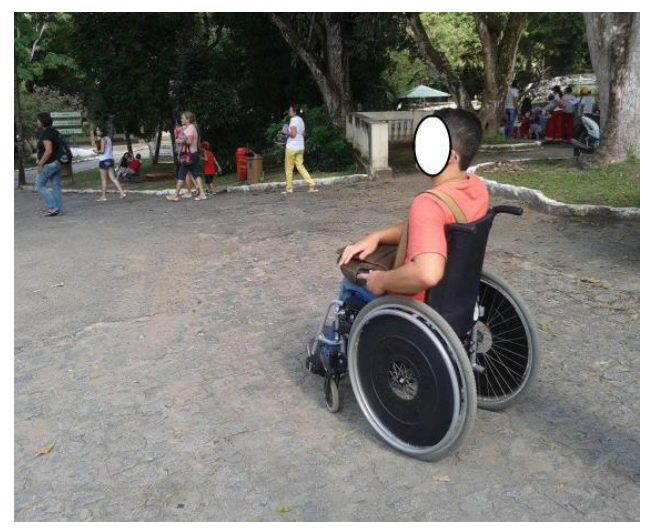

Fonte: Acervo pessoal. 


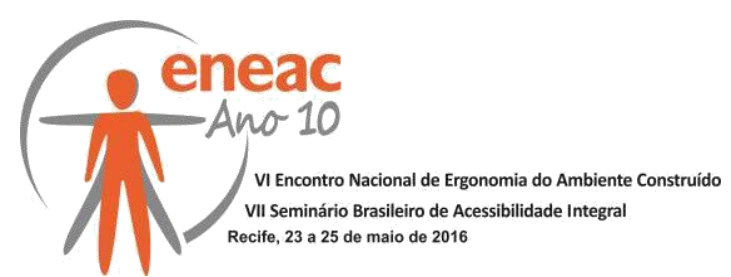

Para se ter acesso ao parquinho há um meio-fio ao redor do mesmo dificultando a passagem do cadeirante. E dentro do parquinho o piso é de areia fofa, que impossibilita o trafego de cadeirantes dentro do mesmo (Foto 02) e (Foto 03).

Figura 02: Acesso inadequado.

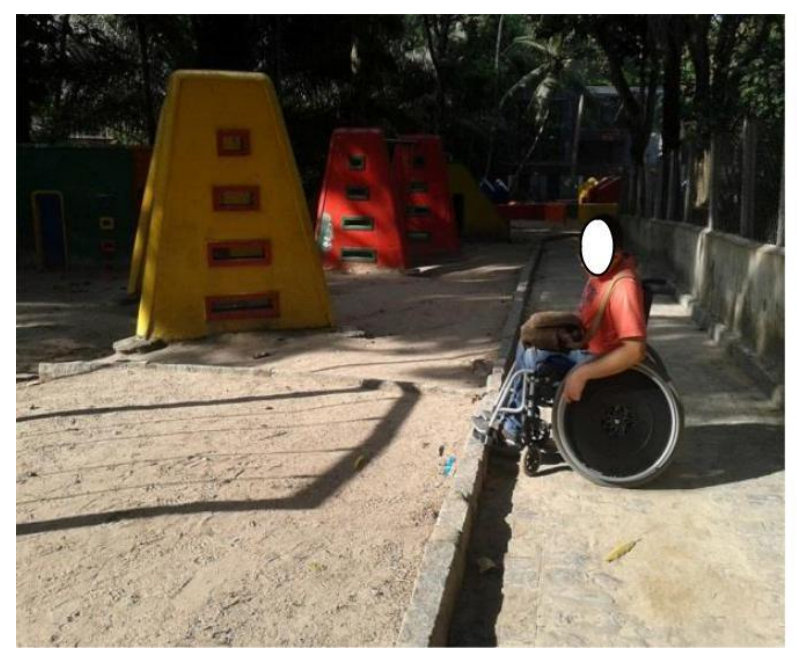

Fonte: Acervo pessoal.
Figura 03: Caminho de acesso de areia.

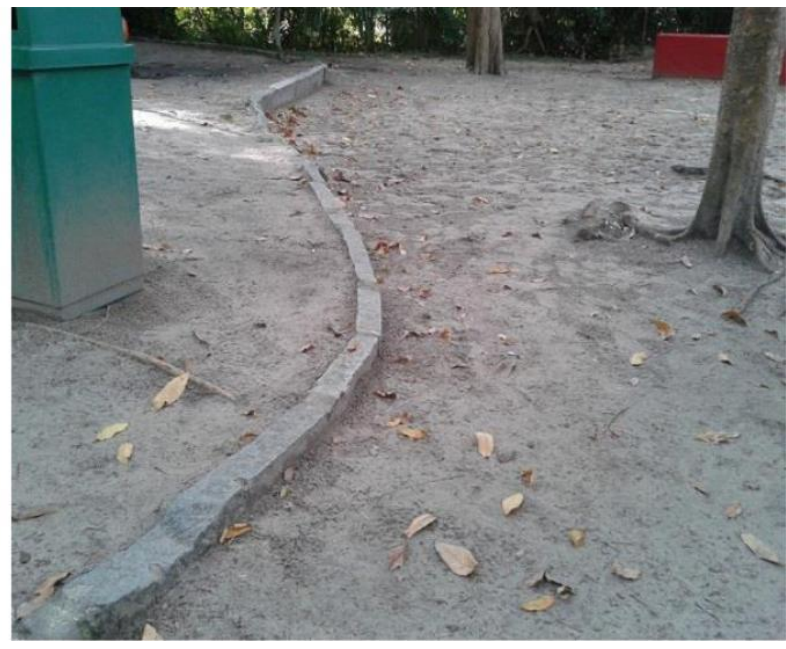

Fonte: Acervo pessoal.

E mencionou que a localidade do primeiro parquinho é ideal, só necessitaria de uma rota acessível. Pois o trajeto até o segundo parquinho que se localiza próximo ao lago dos pedalinhos é longe e de difícil acesso, impossibilitando um cadeirante chegar sozinho até o mesmo, como mostra a (Foto 04).

Figura 04: Acesso a segunda parte parquinho.

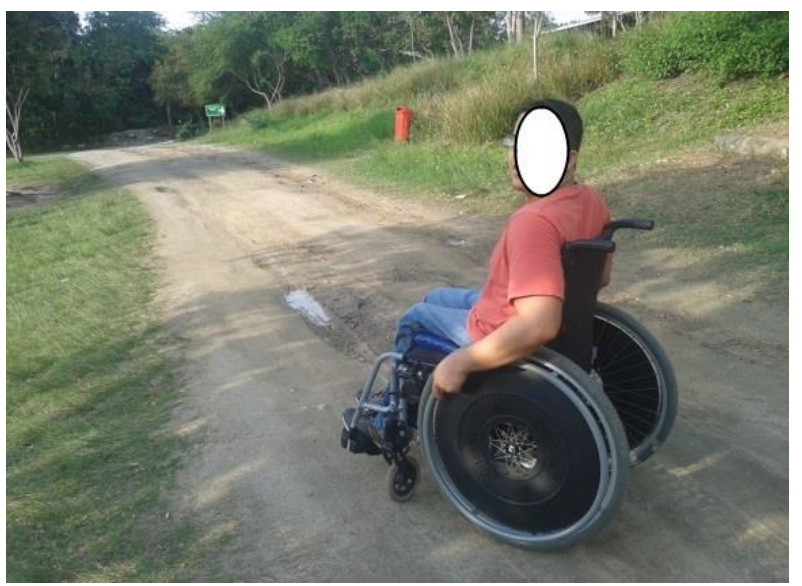

Fonte: Acervo pessoal.

O cadeirante relatou que os brinquedos do Parque Infantil são altos, o que dificulta tanto aos pais para colocarem seus filhos para brincar, quanto para as crianças deficientes de brincarem de forma autônoma nos mesmos. Relata também que os equipamentos são desconfortáveis e são inseguros, pois nenhum brinquedo tem sequer uma barra de sustentação para a criança se apoiar. 


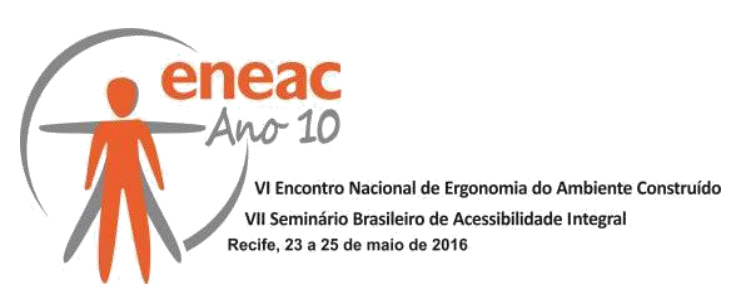

\section{PROPOSTAS PARA OS EQUIPAMENTOS DE LAZER}

O trabalho de pesquisa observou que crianças com deficiência auditiva e visual não necessitam de brinquedos específicos para que os mesmos possam brincar, apenas sinalização adequada (com identificação de precaução, quanto a segurança, identificação de altura e de peso), com pisos táteis e descrição dos brinquedos em braile. Já as crianças com deficiência física e mental necessitam de equipamento que proporcionem autonomia e segurança, levando em consideração também o conforto. Para propor equipamentos de lazer, foram pesquisados projetos já existentes, que serão apresentados a seguir (Figura 05 e 06):

\section{Figura 05: Equipamento passagem}

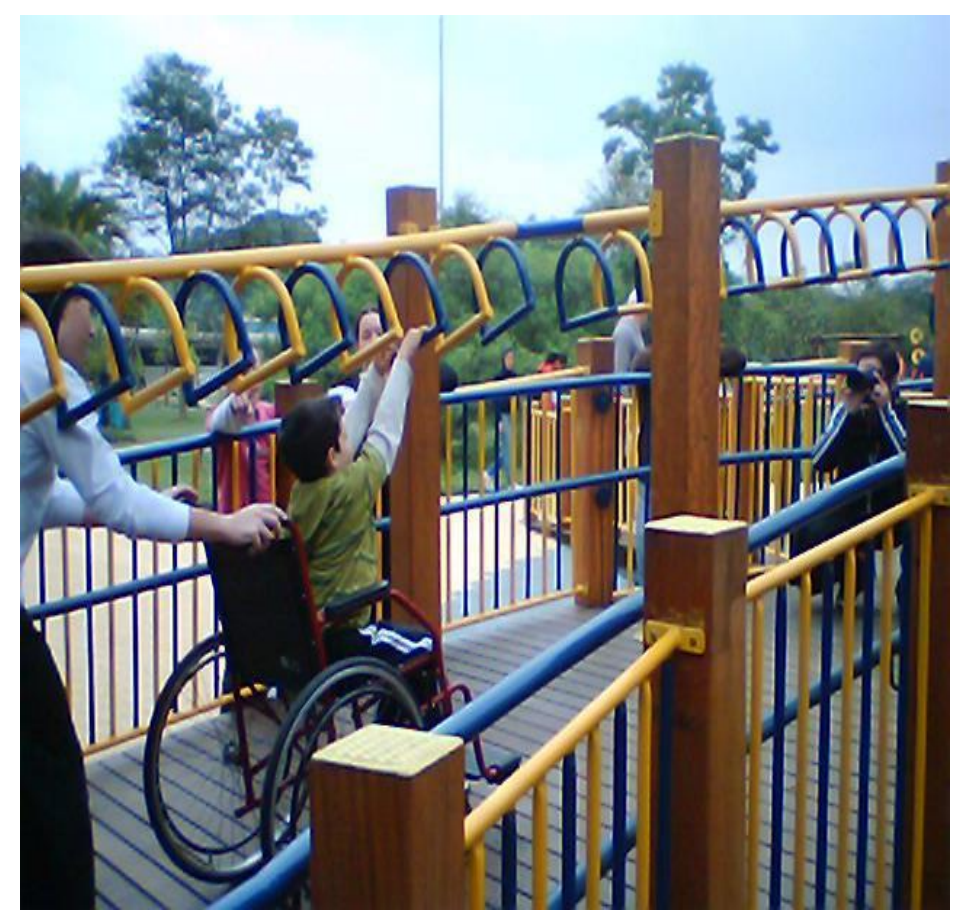

Fonte: Axel Grael, evento-brincando-com-as-diferencas, acesso maio de 2014.

Este equipamento foi criado por Rodolfo Ficher e sua esposa Cláudia Petlick. E o brinquedo estimula também a inclusão, pois a criança cadeirante brincará no equipamento na companhia dos pais ou de outras crianças. Segundo Rudy, como é mais conhecido, "O parque é para todos e pode ser aproveitado tanto por crianças com deficiência como por crianças sem deficiência". E "Temos ainda a intenção de transformá-lo em polos de atividades culturais e esportivas para pessoas com deficiência".

\section{CONCLUSÃO}

Como foi observado no devido trabalho de pesquisa, a falta de acessibilidade, que limita o direito de um individuo de ir e vir. Portanto deve-se sugestionar ao Parque Arruda Câmara uma melhor acessibilidade, para chegada até o parquinho e dentro dele, pois foi observado 


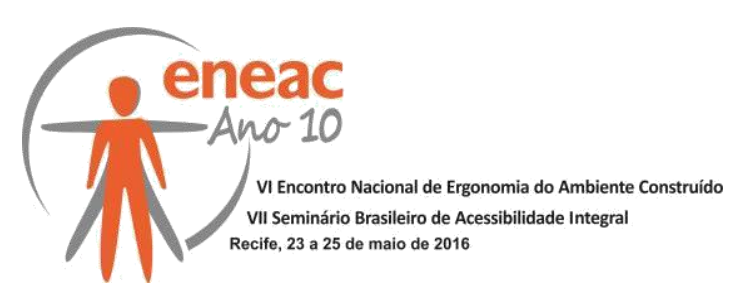

através de entrevista, que uma das maiores dificuldades por parte das crianças deficientes e de seus acompanhantes, seria a dificuldade de locomoção de acesso até o mesmo.

E propor, através de projetos já elaborados, equipamentos de lazer que tentam incluir o maior número de crianças em parques infantis, e direciona-los ao Parque Infantil do Parque Arruda Câmara, com o intuito de trazer mais inclusão para crianças deficientes nos ambientes de lazer.

Portanto, tais sugestões serão imprescindíveis também para o desenvolvimento cógnito, das crianças deficientes, onde as mesmas podem buscar sua liberdade, dentro de um ambiente de lazer, ou seja, conhecer o mundo, mesmo necessitando de um equipamento para sua locomoção (muleta) ou estando em uma cadeira de rodas.

\section{REFERENCIAS BIBLIOGRÁFICAS}

ASSOCIAÇÃO BRASILEIRA DE NORMAS TÉCNICAS. NBR 9050: Acessibilidade de Pessoas Portadoras de Necessidades.

BRASIL. Ministério da Educação. Secretaria de Educação Básica. Parâmetros Básicos de Infraestrutura para Instituições de Educação Infantil. Brasília: MEC/SEB, 1998ba.

BRENDLER, C. F.; BRONDANI, S. A.; SENA, P. P. Carrossel adaptado a PNEs. In:CONGRESSO INTERNACIONAL DE PESQUISA EM DESIGN, 4., Rio de Janeiro. Anais...Rio de Janeiro: ANPED, 2007. $p$ 1-6.

CAMBIAGHI, S Desenho Universal: Métodos e técnicas para arquitetos e urbanistas. São Paulo: Editora Senac, 2007

; CRADDOCK, G. Matching Person and Technology (MPT): assessment process. Technology and Disability, ํㅡ 14, pp.125-131, 2002.

CRUZ, D. M. C.; PFEIFER, L. I. Revisão de literatura sobre o brincar de crianças com paralisia cerebral nas três últimas décadas. Arquivos Brasileiros de Paralisia Cerebral,São Paulo, volume 2, número 05, p. 04-13, jan./abr. 2006.

DAHROUJ, L. S. Design Ergonômico aplicado a produtos destinados à recreação infantil: Projeto de Playground. 2006. 94 f. Trabalho de Conclusão de Curso. (Graduação em Desenho Industrial) - Universidade Estadual Paulista Júlio de Mesquita Filho, Bauru.

Deficiências a Edificações, Espaço, Mobiliário e Equipamento Urbano. Rio de Janeiro: ABNT, 2004. HOCKING, C. Function or feelings: factors in abandonment of assistive devices. Technology and Disability, no 11, pp. $03-11,1999$.

IBGE. Disponível em: http://www.ibge.gov.br/censo/ Instituto Nacional para Reabilitação. Dados da populaão brasileira. Disponível em: http://www.inr.pt/content/1/5/desenho-universal, acesso em maio de 2014.

LAUFER, A M. Recomendações para projeto de brinquedos de recreação e lazer adaptados à criança com paralisia cerebral. 2001. 44 f. Dissertação (Mestrado em Engenharia de Produção) Universidade Federal de Santa Catarina, Florianópolis, 2001.

Lei no 10.098, de 20 de dezembro de 2000. Disponível em: http://www.planalto.gov.br/ccivil_03/leis/110098.htmLei no 11.982, de 2009. Disponível em: http://www.planalto.gov.br/ccivil_03/_Ato2007-2010/2009/Lei/L11982.htm

MAIA, F; NNIEMEYER, L; FREITAS, S. Tecnologia Assistiva: Entendendo o Processo. In: MORO, A.R.P. Ergonomia da sala de aula: Constrangimentos posturais impostos pelo mobiliário escolar. Buenos Aires, n.85, jun. 2005.

MALLIN, V. Uma metodologia de design aplicada ao desenvolvimento de tecnologia assistiva para portadores de paralisia cerebral. Paraná: UFPR, 2004 


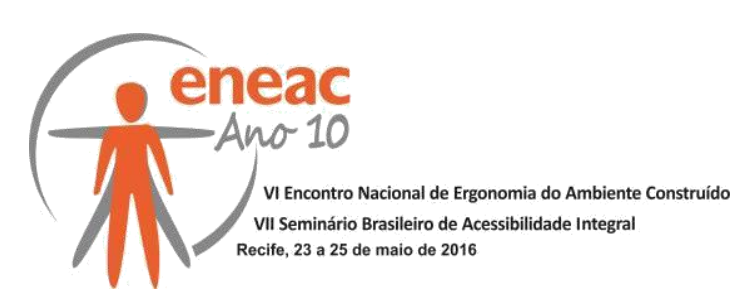

OMS, Organización Mundial de La Salud; OPS, Organización Panamericana de la Salud. Plan de Acción sobre la Salud de las Personas Mayores incluindo el Envelhecimento Activo y Saludable. 144.a Sesión del Comité Ejecutivo, 2009.

ORNSTEIN, Sheila Walbe Org.; PRADO, Adriana R. de Almeida; LOPES, Maria Elisabete (orgs). Desenho Universal. Caminhos da Acessibilidade no Brasil. São Paulo: Annablume, 2010.

Phillips, B. , \& Zhao, H. (1993). Predictors of assistive technology abandonment. Assistive Tecnology.

PORTUGAL. Decreto-Lei n.. 379, de 27 de dezembro de 1997 . Aprova o regulamento que Estabelece as Condições de Segurança a observar na Localização, Implantação, Concepção e Organização Funcional dos Espaços de Jogo e Recreio, Respectivo Equipamento e Superfícies de Impacto. $16 \quad$ p., $1997 . \quad$ Disponível $\quad$ em: <http://www.idesporto.pt/DATA/DOCS/LEGISLACAO/doc072.pdf >. Acessoem: 11 set. 2008.

Programa Brasileiro de Acessibilidade Urbana, 2004; Pelo Ministério das Cidades: http://www.prograd.uff.br/sensibiliza/sites/default/files/Programa_Brasil_Acessivel_Ministerio_das_Cid ades_Novo.pdf

SASSAKI, Romeu Kazumi. Inclusão: construindo uma sociedade para todos. 3.ed. Rio de Janeiro: WVA, 1999.

SCHERER, M. The change in emphasis from people to person: introduction to the special issue on assistive technology. Disability and Rehabilitation, Vol. 24, № 1/2/3, pp. 1-4,2002.

STAINBACK, Susan; STAINBACK, Willian. Inclusão: um guia para educadores. Trad. Magda França Lopes. Porto Alegre: Artes Médicas, 1999.

UNITED STATES ACCESS BOARD. Accessible Play Areas : a summary of accessibility guidelines for play areas. 2005. Disponível em: <http://www.access-board.gov/play/guide/intro.htm>.

VIGOTSKY, L. S. A formação social da mente: o desenvolvimento dos processos psicológicos superiores. Tradução José Cipolla Neto, Luís Silveira Menna Barreto, Solange Castro Afeche. São Paulo: Martins Fontes, 1998.

WERNER, D. Parquinho para todas as crianças. In: Guia de deficiências e reabilitação simplificada: para crianças e jovens portadores de deficiência, famílias, comunidades, técnicos de reabilitação e agentes comunitários de saúde. Brasília: CORDE, 1994. cap. 46, p. 415-426. 